\title{
25
}

\section{Innovations in CSO and SSO Long Term Control Plans}

\author{
Uzair (Sam) M. Shamsi and Ron Ciucci
}

Many cities in the United States are currently developing long term control plans (LTCPs) to control combined sewer overflows (CSO) and sanitary sewer overflows (SSO). Most of these plans are mandated by Clean Water Act regulatory requirements such as consent orders from state environmental protection agencies and consent decrees from the U.S. Environmental Protection Agency (USEPA). These plans are required to recommend a facility plan to meet an appropriate level of CSO and SSO control. Development of these plans requires innovative, efficient and cost effective surveying, mapping, monitoring, modeling, costing and alternative ranking techniques. This chapter presents a case study to illustrate innovative LTCP development techniques used in an LTCP project in Pennsylvania completed in 2011. The chapter focuses on plan development, GIS mapping, GPS surveys, flow monitoring, hydrologic and hydraulic $(\mathrm{H} \& \mathrm{H})$ modeling, model calibration, and public participation techniques used in the project.

\subsection{Introduction}

Combined sewer overflow is defined as a discharge of untreated wastewater from a combined sewer system into the environment prior to reaching treatment facilities, thereby escaping wastewater treatment. A sanitary sewer overflow is defined as a release of untreated or partially treated wastewater from a sanitary sewer system (Water Environment Federation, 2011). When caused by rainfall CSO and SSO discharges are also known as a wet weather overflow. CSO, SSO and wet weather overflow discharges are primarily meaningful in developed countries, which have extensive sewage treatment facilities.

Shamsi, U.M. and R. Ciucci. 2013. "Innovations in CSO and SSO Long Term Control Plans." Journal of Water Management Modeling R246-25. doi: 10.14796/JWMM.R246-25.

(C) CHI 2013 www.chijournal.org ISSN: 2292-6062 (Formerly in Pragmatic Modeling of Urban Water Systems. ISBN: 978-0-9808853-8-5) 
On April 19, 1994, the USEPA published a National Combined Sewer Overflow Control Policy to expedite compliance with the requirements of the Clean Water Act (Federal Register, 1994). The policy required CSO communities to develop LTCPs to limit CSO discharges to four overflows per year or reduce the CSO discharge volume by $85 \%$, among other options.

At a minimum, LTCP development requires completion of the following tasks (Shamsi, 1998; Shamsi and Scally, 1997):

- system characterization using conventional or GPS surveys, system inspection, and GIS mapping;

- hydraulic characterization using flow monitoring and $\mathrm{H} \& \mathrm{H}$ modeling;

- alternative analysis, costing and ranking;

- development of a facility plan; and

- public participation.

During the first ten years of the National CSO Policy, LTCP development was a time consuming and costly process. In the last five years, new tools and technologies have evolved, especially from the large CSO projects, which allows an efficient and cost effective approach to LTCP development. These innovative techniques are described using a case study.

\subsection{Case Study}

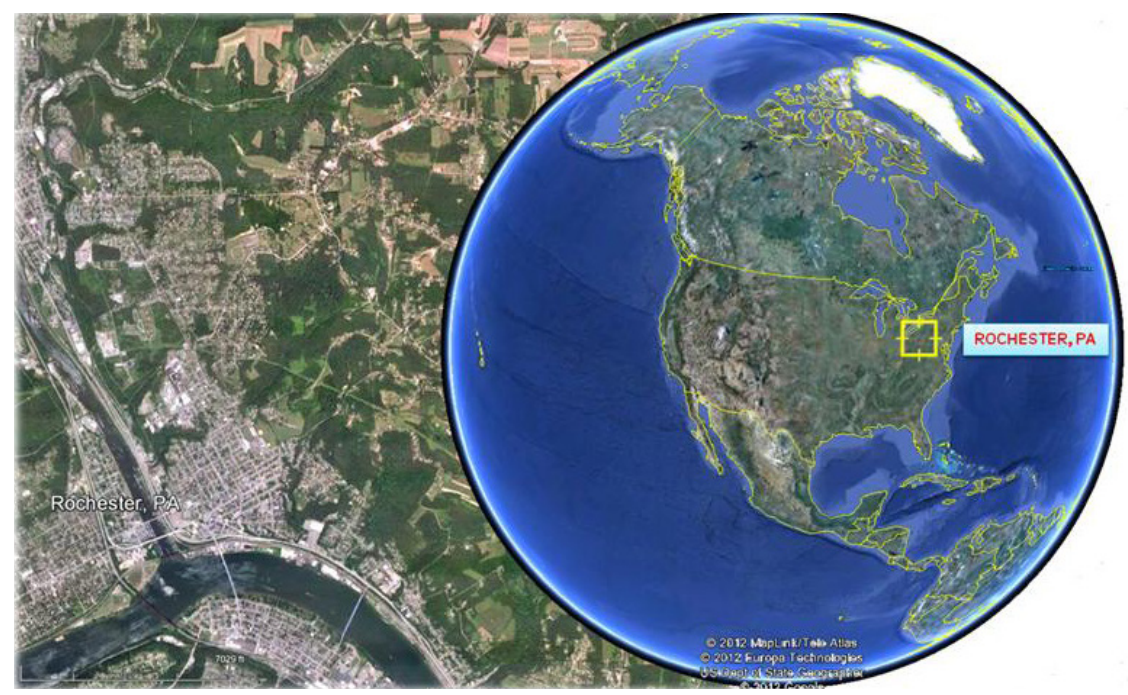

Figure 25.1 Study area location. 
Rochester Area Joint Sewer Authority (RAJSA) is located in southwestern Pennsylvania in Beaver County, about 30 miles $(48.3 \mathrm{~km})$ northwest of Pittsburgh. The location map is shown in Figure 25.1 above. RAJSA owns and operates a waste water treatment plant (WWTP) and interceptor system that treats and conveys wastewater flows from Rochester Borough Sewer and Maintenance Authority (RBSMA), East Rochester Borough, Freedom Borough Collection and Conveyance Authority (FBCCA), Rochester Township Sewer Authority (RTSA), and New Sewickley Township.

Figure 25.2 shows the RAJSA service area map, including municipal boundaries, interceptors and outfalls. The service population is about 9200 and service area is about 1420 acres $\left(5.75 \mathrm{~km}^{2}\right)$. There are ten permitted (six active) CSO outfalls and two SSO outfalls in the RAJSA sewer system. The East Washington Street, Hull Street, 6th Street and 7th Street CSOs were closed subsequently. Modeled typical year (2003) CSO statistics based on $1 \mathrm{y}$ simulation period for the existing conditions are provided in Table 25.1. The RAJSA interceptor system, located along the Ohio and Beaver Rivers, consists of approximately $3.2 \mathrm{mi}(5.1 \mathrm{~km})$ of sewers ranging in size from $10 \mathrm{in}$. $(25.4 \mathrm{~cm})$ to $24 \mathrm{in}$. $(61.0 \mathrm{~cm})$. In 2008, a USEPA consent order mandated RAJSA to develop an LTCP (Section 12, 2008 Consent Order and Agreement, Michael Baker Jr., Inc., 2011).

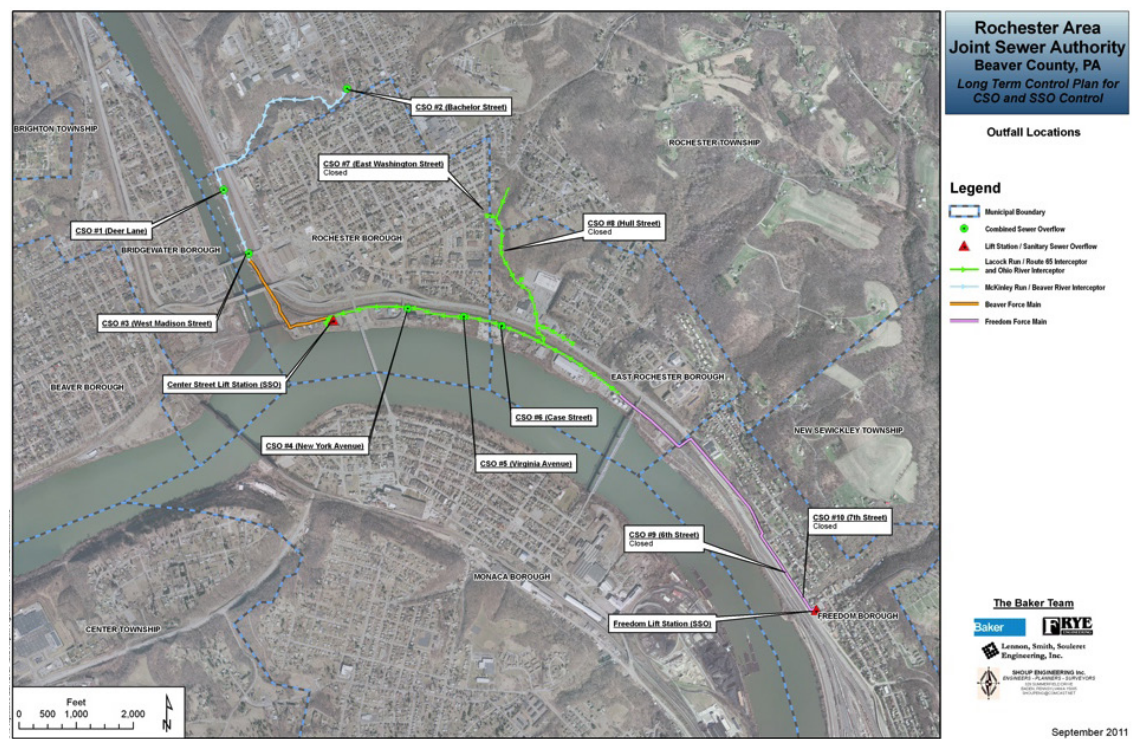

Figure 25.2 Outfall locations. 
Table 25.1 Typical year CSO statistics for the existing conditions.

\begin{tabular}{lccc}
\hline \multicolumn{1}{c}{ CSO Outfalls } & $\begin{array}{c}\text { Number of Overflow } \\
\text { Events }\end{array}$ & $\begin{array}{c}\text { Total CSO Volume } \\
(\mathrm{MG})\end{array}$ & $\begin{array}{c}\text { Duration } \\
(\mathrm{h})\end{array}$ \\
\hline Bachelor St. & 44 & 0.885 & 275 \\
Deer Lane & 76 & 1.75 & 559 \\
West Madison St. & 51 & 7.34 & 299 \\
New York Ave. & 47 & 23.18 & 396 \\
Virginia Ave. & 44 & 0.49 & 330 \\
East Washington St. & 87 & 0.58 & 355 \\
Hull St. & 66 & 0.23 & 290 \\
6th St. & 28 & 0.17 & 241 \\
7th St. & 36 & 0.23 & 270 \\
Case St. & 8 & 0.12 & 64 \\
$\quad$ Totals for CSOs & 487 & 34.98 & 3,079 \\
\hline
\end{tabular}

\subsubsection{LTCP Approach}

In April 2010, RAJSA hired Michael Baker Jr., Inc. (Beaver, Pennsylvania) for the development of the required LTCP (Michael Baker Jr., Inc., 2011). Three southwestern Pennsylvania firms (Lennon, Smith, Souleret Engineering, Inc. (LSSE); Frye Engineering; and Shoup Engineering) served as Baker's sub-consultants. The LTCP development project had an aggressive 21 month schedule with a completion date of December 31, 2011. The LTCP development included nine main tasks:

- characterization, monitoring and modeling;

- public participation;

- consideration of sensitive areas;

- evaluation of alternatives;

- cost and performance considerations;

- operational plan;

- maximization of treatment at the WWTP;

- implementation schedule; and

- post-construction compliance monitoring plan.

The preceding steps culminated in the development of appropriate CSO and SSO control alternatives for RAJSA's and the member municipalities' outfalls. The results of the alternative development, cost estimation, evaluation and identification of the selected alternative were presented in the LTCP report (Michael Baker Jr., Inc., 2011).

\subsubsection{LTCP Control Levels}

The RAJSA LTCP was developed using the presumption approach of the National CSO Policy. The presumption approach operates under the premise that 
it is presumed that the RAJSA could meet water quality standards by implementing CSO controls that will not allow more than an average of four overflow events per year or provide an $85 \%$ capture rate during wet weather on an annual average system wide basis.

Based on the RAJSA system model, CSO statistics (volume and peak flow) were generated for every outfall as well as a selection of outfall groupings for control levels of $0,4,8,12$ and 20 overflow events/y based on a typical year storm. CSO statistics were also generated based on the $85 \%$ capture of wet weather during the typical year. Highest ranked alternatives were developed for the various CSOs using the overflows/y criteria, and they were advanced to the $85 \%$ capture analysis to develop the final alternatives. The approach was discussed with the Pennsylvania Department of Environmental Protection prior to and during the development of this LTCP.

CSO control alternatives for RAJSA's six active CSO outfalls were sequentially developed. The project team listed $>70$ potential CSO control technologies that are currently being utilized throughout the country. The team also developed a list of applicable screening criteria that could be used to eliminate control technologies that were considered infeasible. This process resulted in surviving technologies for CSO control, for use in forming alternatives; these technologies were used to develop CSO control alternatives for the following categories:

- outfall specific: technologies that can be applied at every single outfall;

- consolidated alternatives: technologies that can be applied to several outfalls (such as a large storage basin);

- $\quad$ system wide alternatives: technologies that can be applied to the overall system (storage tunnels were selected as the major technology that can be applied system wide); and

- $85 \%$ capture alternatives: technologies that result in the capture of at least $85 \%$ of the wet weather flow on an average annual, system wide basis.

SSO control alternatives for RAJSA's two SSO outfalls were sequentially developed. Since SSOs are illegal, control is limited to conveyance to the waste water treatment plant or storage. These two technologies were used in forming alternatives for the following categories:

outfall specific: technologies that can be applied at every single outfall; and consolidated alternatives: technologies that can be applied to several outfalls (such as a large storage basin). 


\subsubsection{Alternative Evaluation Process}

The different categories of alternatives were formed and evaluated. Prior to the evaluation, the project team presented the evaluation factors to the RAJSA, various municipal and authority boards and the general public via the CSO plan advisory committee (CPAC). Stakeholders were provided the evaluation factors and weighting criteria and given the opportunity to comment. A summary of the major categories and weighting factors is shown in Table 25.2.

Table 25.2 Alternative evaluation weighing factors.

\begin{tabular}{llc}
\hline \multicolumn{1}{c}{ Criteria Group } & \multicolumn{1}{c}{ Criterion } & Weight Factor \\
\hline Economic factors & $\begin{array}{l}\text { Present worth cost } \\
\text { Overflow volume reduction, bacteria } \\
\text { discharge reduction, solids \& floatable } \\
\text { Water quality, public health \& } \\
\text { environmental impacts }\end{array}$ & $25 \%$ \\
Public factors & $\begin{array}{l}\text { Community disruption, potential for } \\
\text { nuisances (odor, noise), multiple bene- } \\
\text { fit opportunities, environmental justice }\end{array}$ & $20 \%$ \\
Operational impacts & $\begin{array}{l}\text { Ease of operation and maintenance, } \\
\text { reliability, O\&M consistency } \\
\text { Constructability, ability for expansion, } \\
\text { land acquisition }\end{array}$ & $15 \%$ \\
\hline
\end{tabular}

The project team utilized existing cost curves and a costing tool spreadsheet to develop planning level present worth, capital, and operation and maintenance costs of the alternatives. The cost curves were obtained from recent regional and national wet weather projects and supplemented with local cost data.

\section{Outfall Specific}

The resulting CSO control technologies were used to develop various levels of control for the evaluation. The various technologies were then evaluated, using economic and non-economic factors, to determine the highest scoring control technology for each outfall for the predetermined control levels $(0,4$, $8,12,16$ and 20 overflows). At four of the six CSO outfalls, complete sewer separation was the highest scoring alternative, and at the other two, subsurface storage facilities were the highest scoring alternative. The four sewersheds that received the highest score for sewer separation were not evaluated further and were subsequently considered final alternatives. The two sewersheds that received the highest score for subsurface storage were carried forward to the consolidated and $85 \%$ capture analysis. The highest ranking outfall specific CSO control technologies for various control levels are presented in Table 25.3. 
Table 25.3 Highest ranked alternative for CSOs for outfall specific evaluation.

\begin{tabular}{lccccc}
\hline \multirow{2}{*}{ CSO } & \multicolumn{5}{c}{ Level of Control: Number of Untreated CSOs/y } \\
& 0 & 4 & 8 & 12 & 20 \\
\hline Bachelor Street & CSS & CSS & CSS & CSS & CSS \\
Deer Lane & CSS & CSS & CSS & CSS & CSS \\
West Madison St. & ST & ST & ST & ST & ST \\
New York Avenue & ST & ST & ST & ST & ST \\
Virginia Avenue & CSS & CSS & CSS & CSS & CSS \\
Case Street & CSS & CSS & CSS & N/A & N/A \\
\hline CSS Cor
\end{tabular}

CSS: Complete sewer separation

ST: Storage tank

\section{Consolidated}

Consolidated alternatives were also formed and evaluated. A consolidated alternatives evaluation consists of combining the highest ranking alternatives from the outfall specific evaluation into larger (consolidated) facilities and re-scored in the same process. As a result of the outfall specific analysis with the majority of the sewersheds scoring high in the sewer separation category, consolidating the remaining storage facilities did not prove to be economically feasible. As such, no consolidated alternatives were carried forward to the final recommendation.

\section{$85 \%$ Capture}

The highest ranked alternatives from the outfall-specific evaluation were carried forward to the $85 \%$ capture analysis. The $85 \%$ capture analysis was used to determine the final sizing of the two storage facilities, in order to allow $15 \%$ wet weather discharge in the whole combined sewer system, based on an annual average.

\section{WWTP Upgrade}

Once the $85 \%$ capture analysis was complete, the four separated areas and the four subsurface storage facilities were carried forward to the WWTP upgrade alternative evaluation. This evaluation consisted of running the hydraulic model to determine the resultant wet weather flow and volume to the WWTP as a result of these system improvements. The analysis compared storing the wet weather volume at the WWTP with upgrading the WWTP to treat the additional wet weather flow.

\section{Final Alternative Selection}

The project team identified the highest scoring outfall specific alternatives, consolidated alternatives, $85 \%$ capture alternatives and WWTP upgrade alternatives for final recommendations. 


\subsubsection{Plan Description}

The highest ranking alternative for each subsystem includes a mixture of complete sewer separation, subsurface storage facilities, and a WWTP upgrade to treat the additional flow as a result of the requirements of the CSO Control Policy. A summary of the highest ranked alternatives for the entire RAJSA service area is presented in Table 25.4. Design and construction of the proposed facilities is expected to occur during 2013-2017.

Table 25.4 Summary of highest ranked alternatives.

\begin{tabular}{ll}
\hline \multicolumn{1}{c}{ Subsystem } & \multicolumn{1}{c}{ Recommended Alternative Description } \\
\hline Bachelor St. CSO & Complete sewer separation of 26 acres of sewershed area. \\
Deer Lane CSO & Complete sewer separation of 14 acres of sewershed area. \\
& 600000 gallon subsurface concrete storage tank complete with dewater- \\
West Madison St. CSO & ing pumping, screening, connector piping, site preparation and ancillary \\
& functions; located adjacent to the existing West Madison St. pumping \\
& station along the Beaver River. \\
& 600 000 gallon subsurface concrete storage tank complete with dewater- \\
ing pumping, screening, connector piping, site preparation and ancillary \\
few York Ave. CSO & functions; located adjacent to the existing Beaver Valley Bowl along the \\
& Ohio River. \\
Virginia Ave. CSO & Complete sewer separation of 5 acres of sewershed area. \\
Case St. CSO & Complete sewer separation of 7 acres of sewershed area. \\
& 530 000 gallon subsurface concrete storage tank complete with dewater- \\
Freedom lift station SSO & ing pumping, screening, connector piping, site preparation and ancillary \\
& functions; located adjacent to the existing Freedom lift station (this will \\
& control the 5 y design storm). \\
& Upgrade the existing WWTP, which includes improvements to the exist- \\
ing Center St., West Madison and Freedom lift stations, clarifiers, and \\
Center St. SSO/WWTP up- \\
disinfection facilities. The WWTP capacity would increase from 1.4 \\
grade
\end{tabular}

\subsection{GIS Mapping}

GIS mapping is almost essential these days for CSO and SSO planning studies (Water Environment Federation, 2011; Shamsi et al., 2004). GIS data and maps are used in field surveys, system inspection, H\&H modeling, site and alternative screening, and facility planning. All municipalities had CADD drawings of their sewer system which were imported in ArcMap and converted to shapefiles to create a sewer system GIS database.

Sewer system maps for these applications are created by overlaying the sewer network on base maps (aerial photographs, topographic maps and road maps). Not too long ago, project specific custom base maps had to be created, which was both time consuming and costly. In growing communities, project specific base maps became out of date in few years. A web map service 
(WMS) provides online and often free access to latest base maps which is an efficient and cost effective method to add base maps to GIS mapping tasks of a CSO or SSO project. The number of WMSs that implement Open GIS interfaces on the internet is increasing all the time, as more organizations adopt the open standards.

Online mapping has come a long way in the last five years. Google Maps entered the field and added satellite imagery. Microsoft, Yahoo and others quickly followed. However, WMS is different from online mapping as it provides versatile access to geographic datasets from a network of distributed map servers using standards from the Open GIS consortium. Using WMS means you do not need to download and store very large files on your own computer.

WMS can be invoked using a standard web browser by submitting requests in the form of a url (uniform resource locator). WMS is requested by a client application that provides the user with interactive controls. The client application does not have to be web based. The WMS thus becomes a powerful visualization tool from which clients can build customized maps. ESRI's ArcGIS and AutoDesk's AutoCAD are examples of popular geospatial data processing software products that contain WMS connector clients. PCSWMM also provides the WMS capability. The 2012 version of PCSWMM has a single click feature to add Street Maps from MapQuest's OpenStreetMap server shown in Figure 25.3.

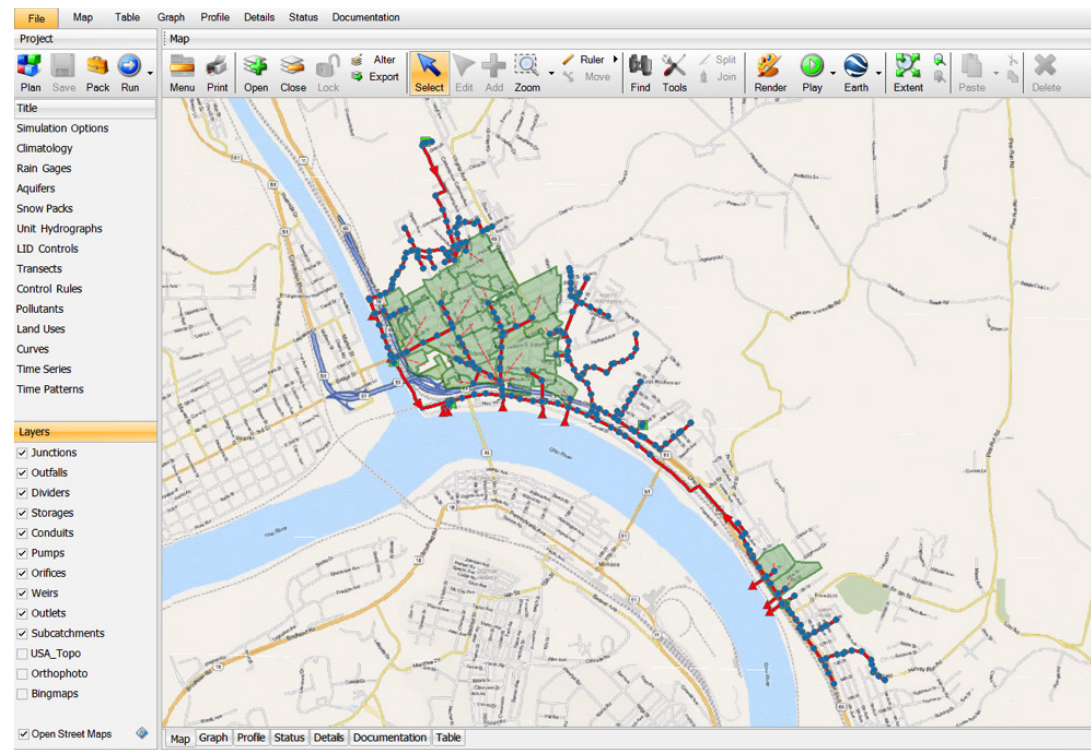

Figure 25.3 RAJSA model overlaid on Mapquest WMS street maps. 


\subsection{GPS Surveys}

Sewer system feature and attribute data were collected using GPS technology for critical features. Critical features were defined as the features which were:

on pipes $\geq 8$ in. $(20.3 \mathrm{~cm})$;

- connected to other structures (e.g. CSO, outfall, pump station or flow monitors);

- connected to large flow sources (industrial, commercial or institutional customers);

- required for modeling; and

- connected to known problem areas (e.g. basement backups, street flooding, manhole overflow, stream inflow, broken sewers or hydraulic restriction).

Paperless survey data were delivered as GIS shapefiles rather than conventional spreadsheets.

Line features should have the following attributes:

- type: sanitary, combined, storm, combined outfall, storm outfall, force main;

- critical: yes or no;

- diameter for circular pipes (in.) (height and width for other shapes);

- shape: circular, rectangular, etc.;

- upstream manhole;

- downstream manhole;

- material;

- upstream invert offset (height between manhole invert and pipe invert); and

- downstream invert offset (height between manhole invert and pipe invert).

Point features should have the following attributes:

- type: manhole, pump station, CSO diversion chamber, outfall;

- top elevation; and

- bottom elevation.

\subsection{Flow Monitoring Data Analysis}

Rainfall derived infiltration and inflow (RDII) into sanitary sewer systems has long been recognized as a source of operating problems in sewer systems. RDII is the main cause of SSOs to basements, streets or nearby receiving waters and can also cause serious operating problems at wastewater treat- 
ment facilities. To assist municipalities in developing plans to mitigate SSO problems, USEPA developed the public domain sanitary sewer overflow analysis and planning (SSOAP) toolbox. The SSOAP toolbox is a suite of computer software tools used for the quantification of RDII and for facilitating the capacity analysis of sanitary sewer systems. This toolbox includes USEPA's Storm Water Management Model Version 5 (SWMM5) for performing dynamic routing of flows through the sanitary sewer systems. SSOAP's SWMM interfacing tool assists users in organizing and incorporating the hydrographs generated by the RDII hydrograph generation tool into the SWMM5 input files (Environmental Protection Agency, 2012b).

For efficient flow monitoring data analysis and model calibration, a hydrograph deconstruction approach was used. Precipitation event data and flow data were loaded into a Microsoft Access database and correlated to match time. This database was analyzed using the SSOAP toolbox to identify component flow parameters (base wastewater flow, ground water infiltration and RDII). Figure 25.4 shows a sample deconstructed hydrograph. Figure 25.5 shows observed vs calibrated hydrograph and computed unit hydrograph RTK parameters. This hydrograph deconstruction approach resulted in efficient analysis of observed flow monitoring data and expedited model calibration task described in the next section.

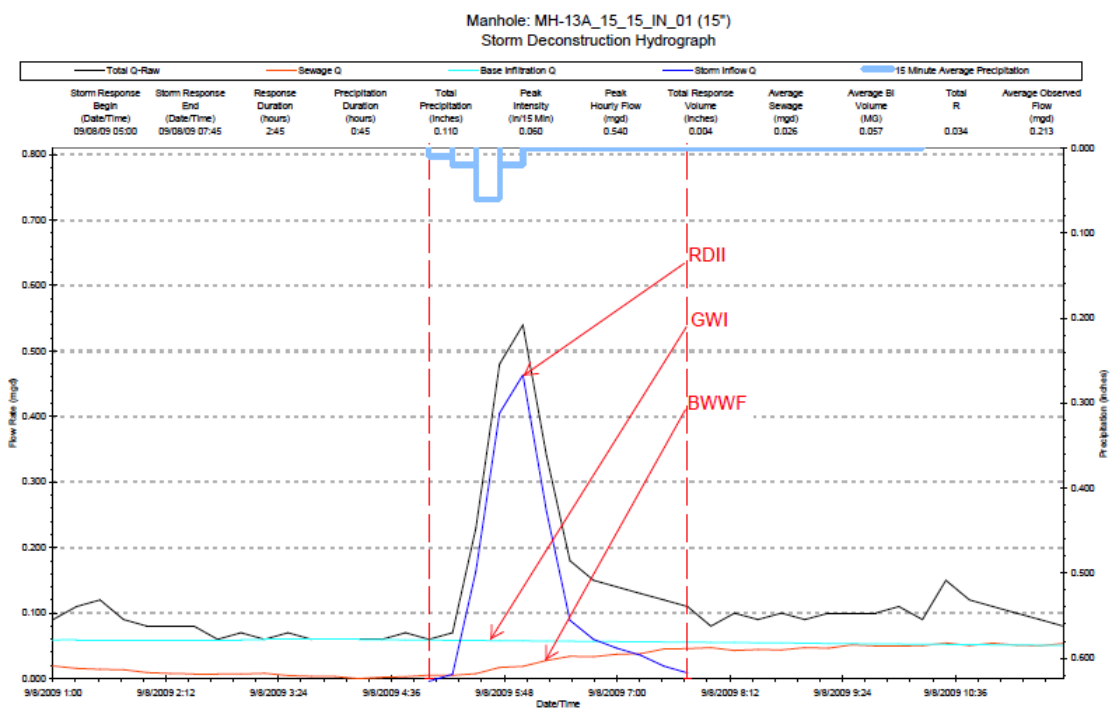

Figure 25.4 Sample deconstructed observed hydrograph. 


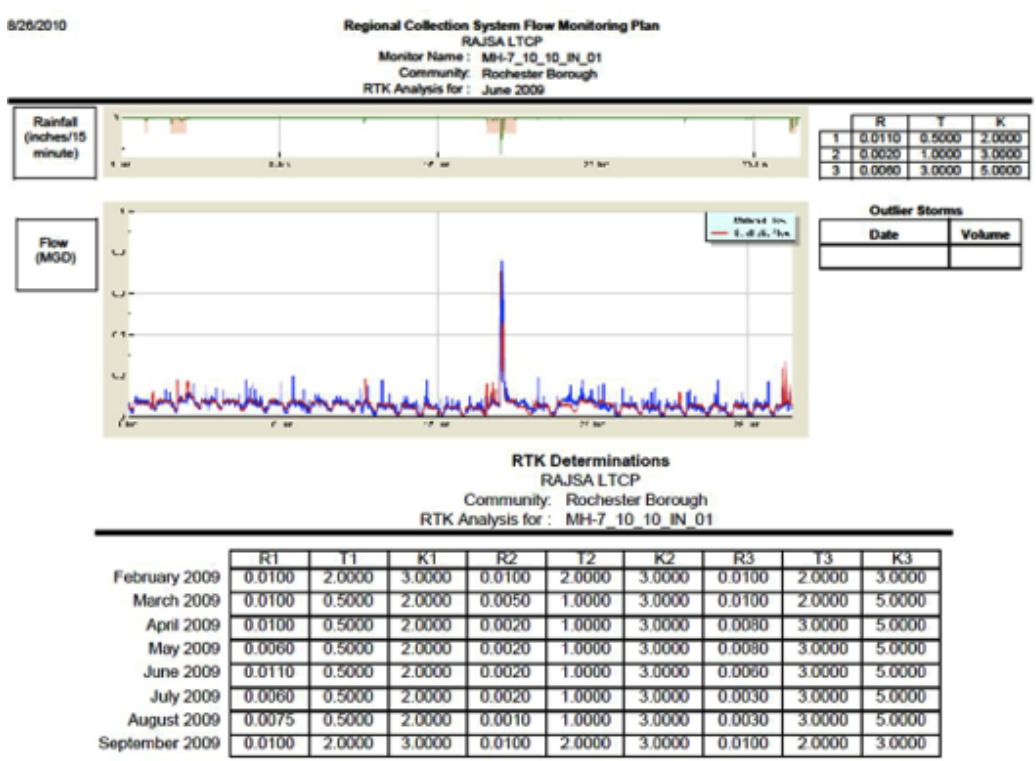

Figure 25.5 Observed vs calibrated hydrograph and computed unit hydrograph RTK parameters.

\subsection{H\&H Modeling}

H\&H modeling was conducted using CHI's PCSWMM software. Figure 25.3 above shows a screenshot of the PCSWMM model. The model was built by importing ArcGIS shapefiles in PCSWMM. Engineering audits were used for quality control on imported data such as the identification of disconnected nodes (orphans). PCSWMM's wizards and calculators were used to fix any problems. The model included 26 subcatchments, 302 junction nodes, 297 conduit links, 42 RDII (RTK) inflows. The model was run for various design storms and typical year (2003) continuous simulation. At a $30 \mathrm{~s}$ computational time step, continuous simulation required over 1051200 iterations - (365 x $24 \times 60 \times 60) / 30$ - but took $\sim 2 \mathrm{~h}$ to run on the latest desktop computers.

The degree of calibration can be assessed by combining the three hydrograph parameters: volume, peak flow and time-to-peak flow. However, this approach is subjective because generally the three hydrograph parameters do not calibrate equally well. If the volumes are the same but the peak flows are different, is the calibration acceptable? Which parameter should be given a higher priority? There is no universal standard for the adequacy of calibration. Is a $10 \%$ difference acceptable or a $25 \%$ difference reasonable? The integral square error (ISE), given by Equation 25.1, was found to be a good measure 
of goodness-of-fit between observed and modeled hydrographs.

$$
I S E=\frac{\left[\sum_{i=1}^{N}\left(O_{i-M_{i}}\right)^{2}\right]^{1 / 2}}{\sum_{i-1}^{N} O_{i}} \times 100
$$

where:

$O_{i}=$ observed hydrograph value at time $i$,

$M_{i}=$ modeled hydrograph value at time $i$, and

$N=$ number of hydrograph values.

Table 25.5 provides goodness of fit ratings for different ISE ranges.

Table 25.5 Goodness of fit ratings for model calibration.

\begin{tabular}{cc}
\hline ISE Range & Rating \\
\hline $0-3$ & Excellent \\
$3.1-6$ & Very good \\
$6.1-10$ & Good \\
$10.1-25$ & Fair \\
$>25$ & Poor \\
\hline
\end{tabular}

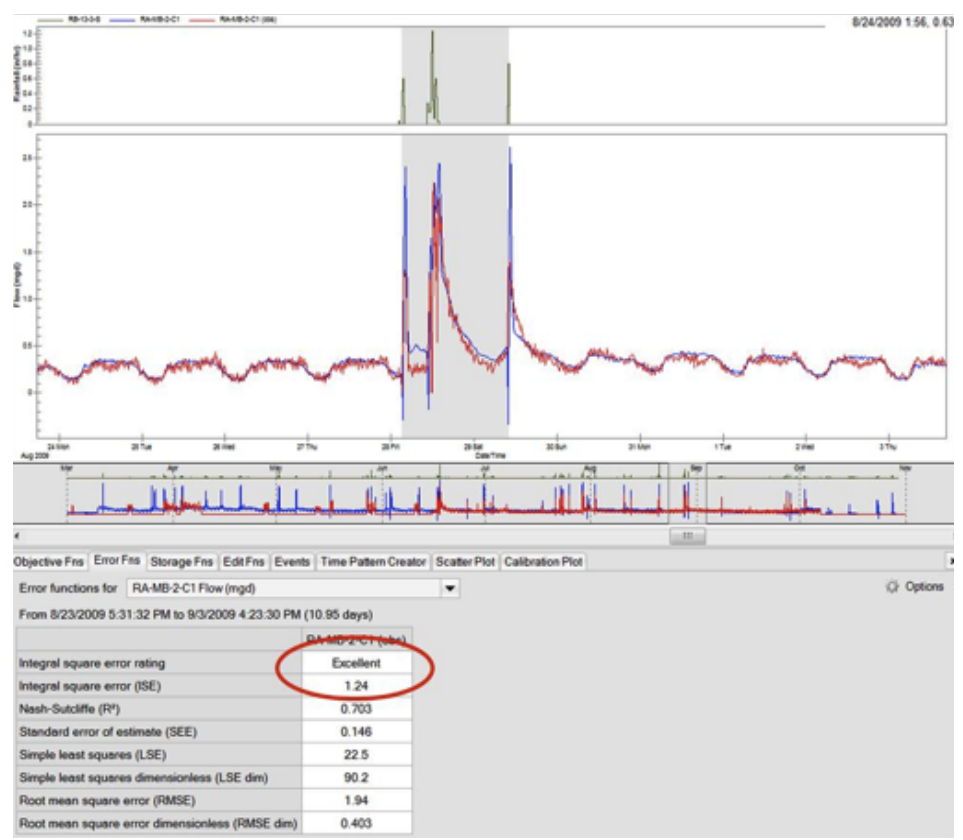

Figure 25.6 Assessment of model calibration using the ISE method. 
In 2011, on the primary author's suggestion, CHI implemented the ISE calibration assessment method in PCSWMM which was used in the RAJSA LTCP project. Figure 25.6 shows a PCSWMM screenshot of ISE implementation in PCSWMM. The ISE for the observed and modeled hydrograph is 1.24, which rates the calibration as excellent. PCSWMM's sensitivity based radio tuning calibration (SRTC) feature was used to expedite the model calibration task.

\subsection{Public Participation}

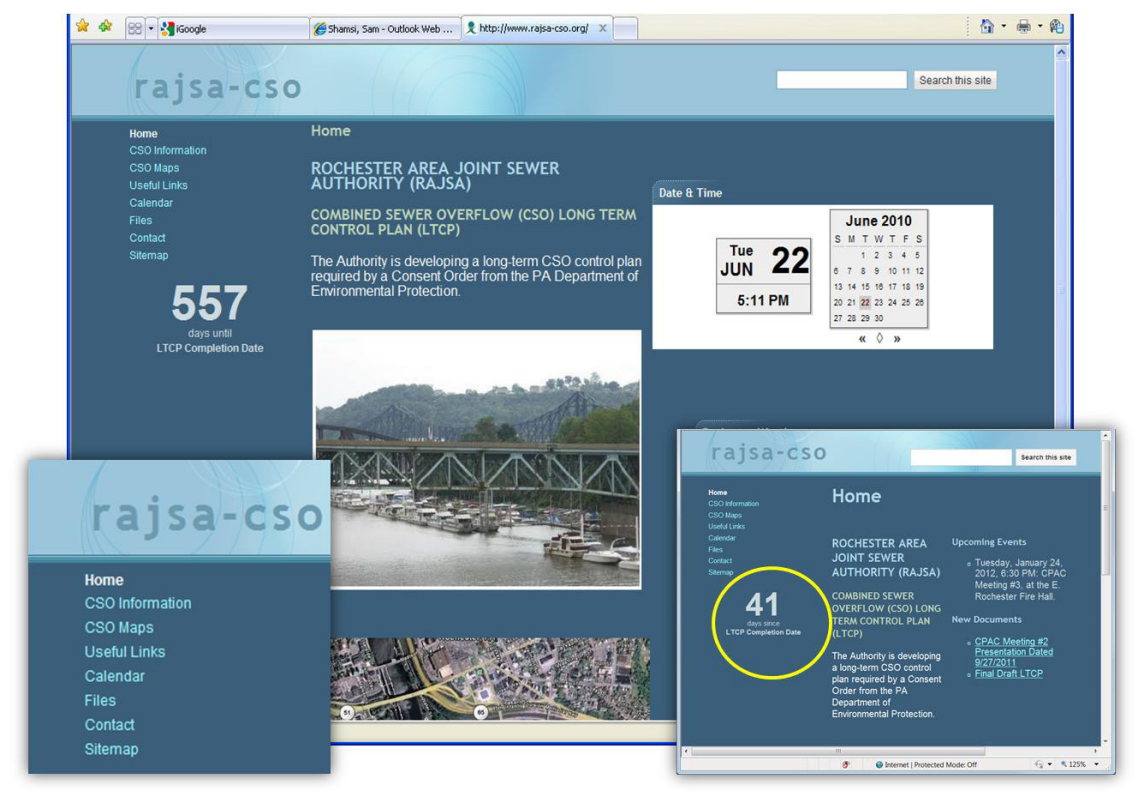

Figure 25.7 Public participation web site.

While municipal involvement and public awareness are mandated at the federal, state and local levels, it is vitally important to convey a clear and concise message to the public through the public awareness process. In keeping with this idea, the RAJSA and the individual municipal entities used a robust public awareness process that included presentations to the citizens of the various municipalities through public meetings, websites and informational flyers. A public participation program was initiated as part of this project. The goals of the program were to involve citizens in the LTCP process, especially in the areas of alternative development and financial impacts to the service area. RAJSA's program included the formation of a CSO plan advisory com- 
mittee. In addition to the public being present at its meetings, the committee had at least one representative from each municipality. These programs were designed to inform as well as solicit input from stakeholders.

The consultant developed a website, www.rajsa-cso.org, that was used to post information on CSOs, meeting notices and documents that were developed during the project. It also showed the number of days remaining to complete the LTCP. A screenshot of the website is shown in Figure 25.7 above. A project portal was created for the project team to exchange documents, especially large files. Project management (budget, time sheets, expense reports, and invoicing) was supported by Oracle's Enterprise Resource Planning software.

Also, it is important to recognize that moving forward, the RAJSA and the member municipal entities have engaged the public as part of the process in developing and implementing this long term control plan. Close cooperation and coordination between all parties helped to ensure that a consistent and concise message is conveyed to the public. Cooperation and involvement permitted RAJSA and all municipal entities to capitalize on opportunities to share public information and resources, thereby containing and limiting costs in preparing a single unified long term control plan as required under the Consent Order and Agreement.

\subsection{Conclusions}

Innovations in mapping, monitoring, modeling, and costing can help completion of technically sound sewer overflow control plans in a reasonable time, and at a reasonable cost. These innovations include public domain (online) GIS-ready maps, GPS surveys, public domain software for using flow monitoring data in models, affordable modeling software for efficient model development from existing GIS and CADD data and efficient model calibration and verification, spreadsheet-based automated tools for costing and ranking alternatives, and web based project management, project portal, and public participation sites. These innovations were used by RAJSA's project team in a $2011 \mathrm{CSO} / \mathrm{SSO}$ LTCP.

\subsection{Acknowledgments}

The authors would like to thank RAJSA for providing an opportunity to work on the RAJSA LTCP project and giving permission to publish this paper. We also thank project prime consultant Michael Baker Jr., Inc. for providing the project information presented in this paper; and sub-consultants Lennon, 
Smith, Souleret Engineering, Inc., Frye Engineering, and Shoup Engineering for their valuable contributions to the project presented in this paper.

\section{References}

Environmental Protection Agency. 2012a. Web Page. Sanitary Sewer Overflows and Peak Flows. http://cfpub.epa.gov/npdes/home.cfm?program_id=4. Page Visited May 2, 2012 .

Environmental Protection Agency. 2012b. Web Page. Sanitary Sewer Overflow Analysis and Planning (SSOAP) Toolbox. http:/www.epa.gov/nrmrl/wswrd/wq/models/ ssoap/. Page Visited June 27, 2012.

Federal Register. 1994. Combined Sewer Overflow Control Policy. Volume 59, No. 75, April 19, 1994, pp. \#18688-18698.

Michael Baker Jr., Inc. 2011. Long Term Control Plan Report for the Rochester Area Joint Sewer Authority. Beaver, Pennsylvania. www.mbakercorp.com

Shamsi, U.M., E. Speer, C. Horne "Enhancing Productivity through Applications Development," Chapter 5 in GIS Implementation for Water and Wastewater Treatment Facilities, Manual of Practice No. 26, WEF, 2004.

Shamsi, U.M. 1998. Thinking Small. Water Environment and Technology, Water Environment Federation, March 1998.

Shamsi U.M., Scally, C. 1997. Are the CSO Requirements Different for Small Communities. WEFTEC '97, Annual Conference and Exposition, WEF, Chicago, October 1812, 1997.

Water Environment Federation. 2011. Prevention and Control of Sewer System Overflows, Manual of Practice No. 17, WEF. 